\title{
Pulmonary exposure to single-walled carbon nanotubes does not affect the early immune response against Toxoplasma gondii
}

Linda Swedin $^{1+}$, Romanico Arrighi ${ }^{2,3+}$, Britta Andersson-Willman ${ }^{4}$, Ashley Murray ${ }^{5,7}$, Yunying Chen ${ }^{4}$, Mikael C I Karlsson ${ }^{4}$, Susanna Kumlien Georén ${ }^{6}$, Alexey V Tkach ${ }^{5}$, Anna A Shvedova ${ }^{5,7}$, Bengt Fadeel', Antonio Barragan ${ }^{2,3}$ and Annika Scheynius ${ }^{4^{*}}$

\begin{abstract}
Background: Single-walled carbon nanotubes (SWCNT) trigger pronounced inflammation and fibrosis in the lungs of mice following administration via pharyngeal aspiration or inhalation. Human exposure to SWCNT in an occupational setting may occur in conjunction with infections and this could yield enhanced or suppressed responses to the offending agent. Here, we studied whether the sequential exposure to SWCNT via pharyngeal aspiration and infection of mice with the ubiquitous intracellular parasite Toxoplasma gondii would impact on the immune response of the host against the parasite.
\end{abstract}

Methods: C57BL/6 mice were pre-exposed by pharyngeal administration of SWCNT ( $80+80 \mu \mathrm{g} / \mathrm{mouse}$ ) for two consecutive days followed by intravenous injection with either $1 \times 10^{3}$ or $1 \times 10^{4}$ green fluorescence protein and luciferase-expressing T. gondii tachyzoites. The dissemination of $T$. gondii was monitored by in vivo bioluminescence imaging in real time for 7 days and by plaque formation. The inflammatory response was analysed in bronchoalveolar lavage (BAL) fluid, and by assessment of morphological changes and immune responses in lung and spleen.

Results: There were no differences in parasite distribution between mice only inoculated with $T$. gondii or those mice pre-exposed for 2 days to SWCNT before parasite inoculum. Lung and spleen histology and inflammation markers in BAL fluid reflected the effects of SWCNT exposure and T. gondii injection, respectively. We also noted that CD11C positive dendritic cells but not F4/80 positive macrophages retained SWCNT in the lungs 9 days after pharyngeal aspiration. However, co-localization of T. gondii with CD11C or F4/80 positive cells could not be observed in lungs or spleen. Pre-exposure to SWCNT did not affect the splenocyte response to T. gondii.

Conclusions: Taken together, our data indicate that pre-exposure to SWCNT does not enhance or suppress the early immune response to $T$. gondii in mice.

Keywords: Carbon nanotubes, Bioluminescence imaging, Inflammation markers, Lung and spleen immunohistology, Dendritic cells, Macrophages, Toxoplasma gondii

\footnotetext{
* Correspondence: annika.scheynius@ki.se

†Equal contributors

${ }^{4}$ Translational Immunology Unit, Department of Medicine Solna, Karolinska Institutet, Stockholm, Sweden

Full list of author information is available at the end of the article
} 


\section{Background}

Carbon nanotubes (CNT), with their unique physicochemical properties, yield numerous technological advantages for novel applications that are expected to drive industrial growth. As a consequence, large quantities of CNTs may reach the environment, and this may inadvertently result in human exposure. Hence, there is an urgent need for the assessment of potential impacts and health effects of CNTs [1]. The unusual properties of CNTs may underlie unique biological activities that may be exploited for biomedical applications, but insufficient research has been undertaken to explore their potential adverse effects on human health. Our earlier studies have shown that SWCNT induced a robust acute inflammation with a very early onset of the formation of granulomas and interstitial fibrosis in the lungs of C57BL/6 mice [2,3]. Several lines of evidence suggested that exposure to respirable CNT could modulate innate immunity and intervene with host resistance to microbial infections [2-5]. Thus, we have previously shown that exposure to SWCNT followed by Listeria monocytogenes (LM) infection resulted in decreased pulmonary clearance of bacteria [2].

Toxoplasma gondii is an obligate intracellular protozoan parasite that infects virtually all warm-blooded vertebrates. Up to one third of the global human population is chronically infected [6]. Following primary infection, the tachyzoite stage of the parasite disseminates widely in the organism. Differentiation of tachyzoites into tissue cyst stages (bradyzoites), predominantly in the brain, results in chronic asymptomatic infection. T. gondii is an opportunistic pathogen and reactivation of the infection can be lethal in individuals with acquired immune deficiencies, e.g. HIV/AIDS, or in individuals with prolonged treatments with immune suppressive drugs, e.g. recipients of organ and bone marrow transplants. Severe manifestations include toxoplasmic encephalitis [6-8] and neurological damage in the developing fetus [6]. Infection in the airways can manifest as severe atypical pneumonia [9-11].

The onset of cell-mediated immunity against $T$. gondii is accompanied by the transformation of the parasite into tissue cysts resulting in lifelong chronic infection. Cellular immunity mediated by NK cells, T cells, dendritic cells (DC), macrophages, and activity of type 1 cytokines (IL-12 and interferon (IFN)- $\gamma$ ) are essential to resist primary infection and for maintenance of quiescence during latent infection $[12,13]$. Mounting evidence indicates that the inherent migratory functions of leukocytes also make them a suitable target (Trojan horse) for T. gondii to mediate its dispersion in the organism [14-16].

Rodents are natural hosts for $T$. gondii and offer a robust infection model [15]. The aim of the present study was to determine whether pre-exposure of mice to SWCNT using the same pharyngeal aspiration protocol as in the infection model with the bacteria L. monocytogenes
[2] would affect the dissemination and host response towards the parasite T. gondii. To evaluate the pathobiology of the Toxoplasma infection in vivo, we used bioluminescence imaging (BLI) which provides a versatile tool for non-invasive assessment with fine temporal resolution $[17,18]$. We also aimed to investigate whether preexposure of mice to SWCNT and T. gondii infection would alter the inflammatory responses, measured as cell counts and the cytokine profile in bronchoalveolar lavage (BAL) fluid, and in lung and spleen histology changes. The data presented here suggest that inhalation of SWCNT before encountering Toxoplasma infection do not interfere with the early immune response to $T$. gondii.

\section{Results}

Pre-administration of SWCNT does not affect the parasitic loads in the spleen and in the lung

In order to monitor the dissemination of the parasite by non-invasive real-time imaging, we utilized PTG Type II GFPluc tachyzoites. Mice were monitored over 7 days post $T$. gondii inoculation, and regardless of initial parasite inoculum, the presence of SWCNT did not significantly affect the parasites development or dissemination as measured by BLI (Figure 1A \& B). The higher inoculation dose of $T$. gondii led to higher parasitic loads over time as expected. Furthermore, strong parasite signals could be clearly detected in the lungs for all parasite treated groups, with the strongest signals detected from the T. gondii $10^{4}$ and SWCNT $+T$. gondii $10^{4}$ groups (Figure 1A). Analysing total photonic emissions from each group of mice showed that although emissions increased over time, particularly after day 4, there was no clear difference in total parasite photonic emissions between $T$. gondii only and SWCNT $+T$. gondii treated mice (Figure 1B, One-way ANOVA, $p>0.05)$. The lungs were studied in more detail to determine whether there was a difference in photonic emissions in that region, but again, no clear differences were detected between $T$. gondii only and SWCNT $+T$. gondii groups on day 7 post-infection (Figure 1C, One-way ANOVA, $\mathrm{p}>0.05$ ). In fact, similar photonic counts between both groups were observed in mice from day 4 onwards (data not shown). Quantification of parasitic load by plaquing assays from lungs and spleens extracted day 7 post-infection confirmed that both organs were heavily infected, with the lungs showing a higher burden per gram tissue than the spleen. However, there was no significant difference in the burdens in relation to the mice pre-treated with SWCNT (Figure 1D, One-way ANOVA, p >0.05). We conclude that the replication and dissemination of $T$. gondii in our mouse model is not obviously hindered or exacerbated by the pre-exposure to SWCNT. 


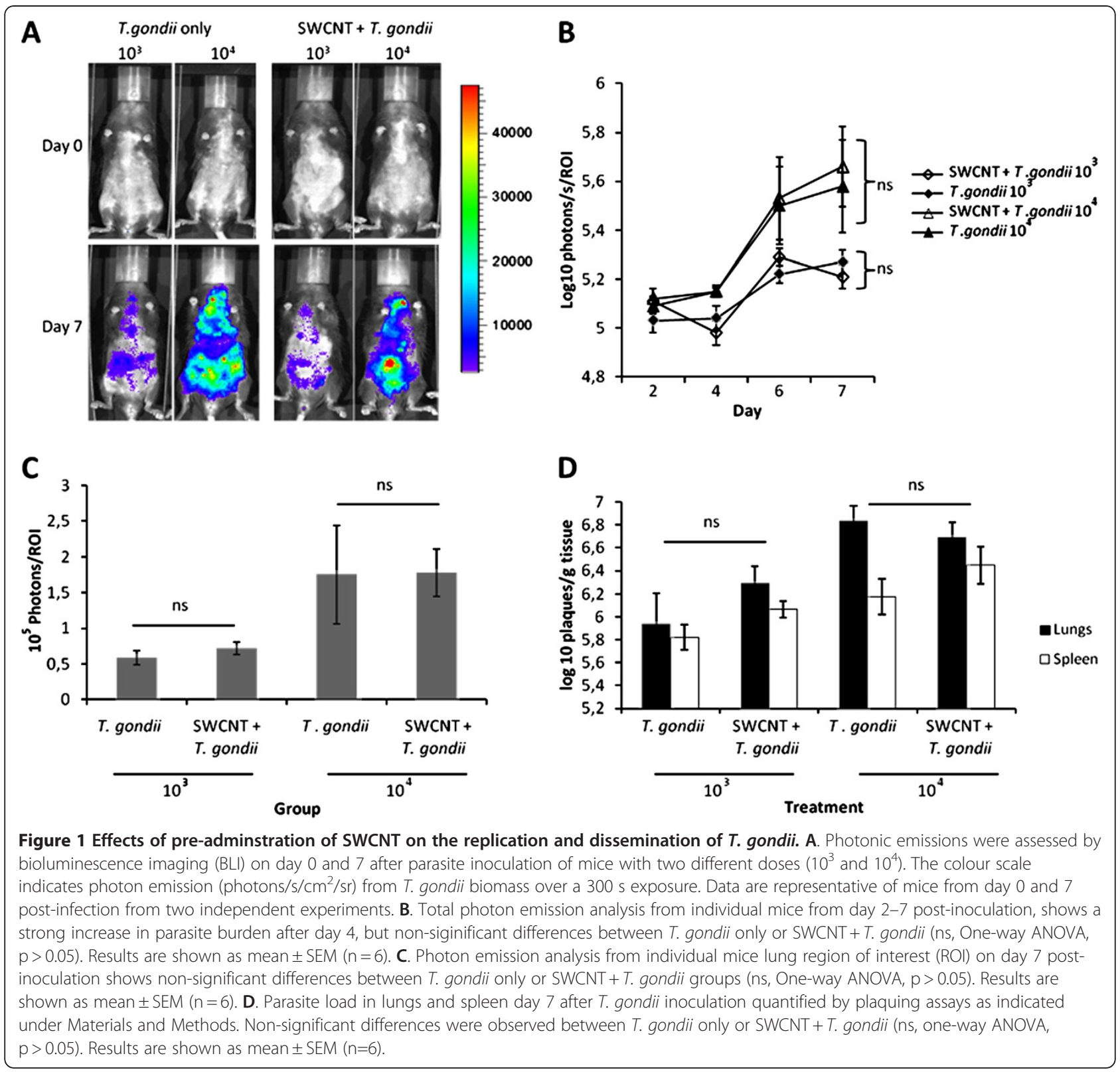

No significant alterations in inflammatory markers in bronchoalveolar lavage fluid following combination exposure

The combined effect of SWCNT treatment and T. gondii infection on the cellular inflammatory response was measured via the accumulation of leukocytes in BAL fluid. Following SWCNT challenge and T. gondii infusion, the total cell number and the number of most leukocytes subtypes, were markedly increased in BAL fluid (One-way ANOVA, $\mathrm{p}<0.05$; Figure 2A) compared to PBS controls. This was true for neutrophils, lymphocytes and especially for macrophages. When comparing the combined treatment with respective controls, i.e.
T. gondii or SWCNT alone, there was a trend, albeit not significant, towards increased total cells and also the number of most leukocytes subtypes, with the exception of eosinophils (One-way ANOVA, p > 0.05; Figure 2A).

To determine cellular damage, total protein concentration and LDH was measured in BAL fluid. Exposure to only SWCNT induced minimal changes in the levels of total protein content and LDH levels compared to the PBS controls (Figure $2 \mathrm{~B}$ and $\mathrm{C}$ ). There was a significant increase in the total protein content and LDH levels in mice infected with the higher concentration of $T$. gondii (One-way ANOVA, p<0.05). However, there were no 


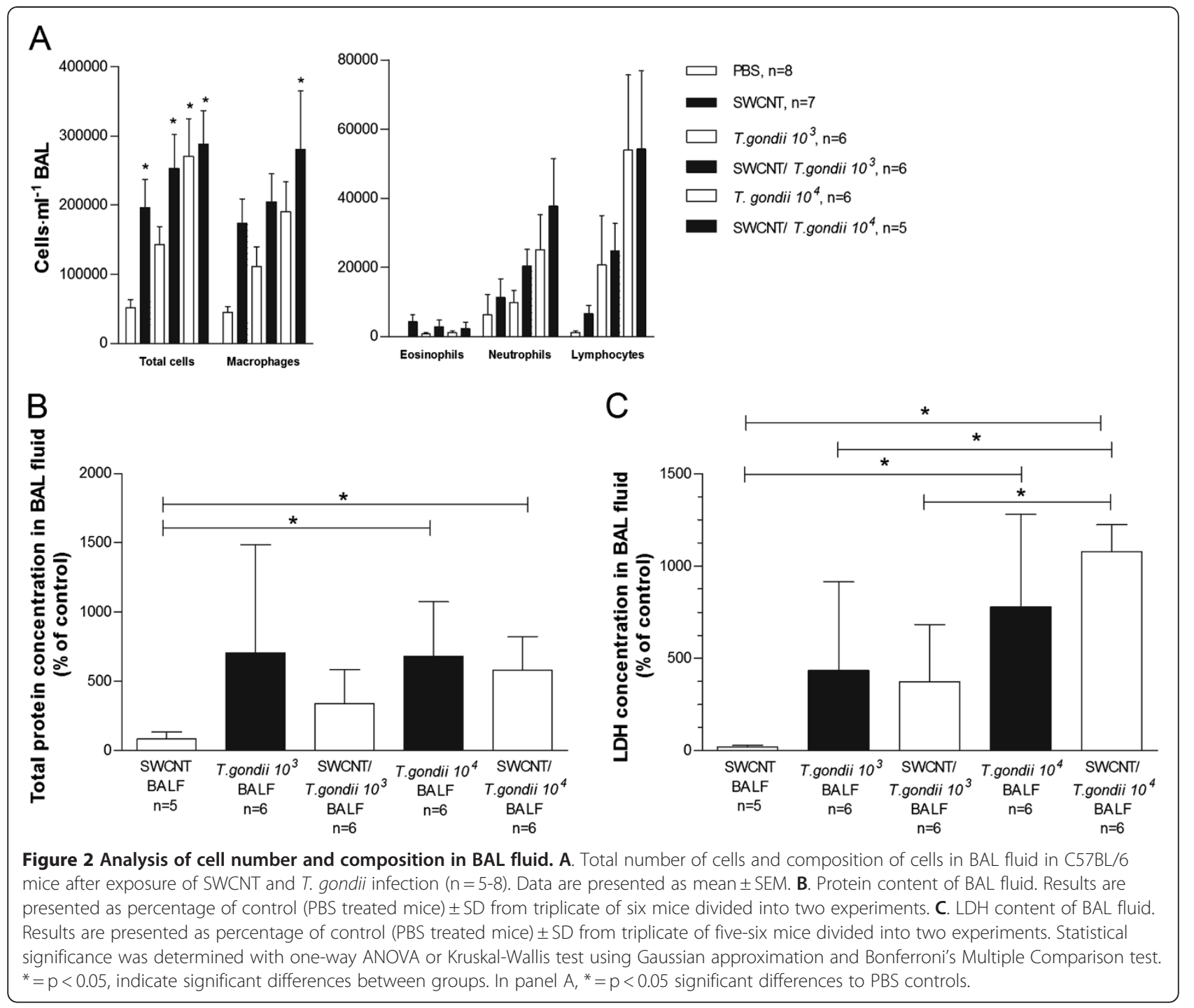

differences between the groups only exposed to $T$. gondii and those also pre-exposed to SWCNT, but a tendency to higher LDH levels could be observed for the combination in mice exposed to the higher concentration of $T$. gondii (Figure 2C).

To clarify the possible contribution of inflammatory mediator cascades in the airway inflammation, a 7-plex panel of cytokines, chemokines and growth factors and a 3-plex panel of TGF $\beta$, were measured in BAL fluid. Exposure to only SWCNT generally induced no change in the levels of mediators in BAL fluid compared to PBS controls at day 10, except for IL-12p40 and TGF $\beta 2$, although not statistically significant (Table 1, one-way ANOVA and further analysed using Bonferroni's Multiple Comparison post hoc test). Although there were increases in all mediators measured after T. gondii infection, these changes did not always reach statistically significant differences compared to PBS controls and mice exposed to SWCNT only, probably due to the small size of the groups (Table 1). Furthermore, there was no clear effect of the combined treatments of SWCNT and infection of $T$. gondii. The TGF $\beta$-plex assay revealed increased levels of TGF $\beta 1$ in mice exposed to SWCNT and/ or T. gondii compared to PBS controls, although not statistically significant (data not shown, one-way ANOVA). There were significantly increased levels of TGF $\beta 2$ in BAL fluid in mice exposed to SWCNT $+T$. gondii $10^{4}$ compared to PBS controls or mice exposed to SWCNT alone and compared to T. gondii $10^{3}$ alone or combined with SWCNT (Table 1, one-way ANOVA, $\mathrm{p}<0.05)$. TGF 33 levels were at the detection range for this particular mediator (data not shown).

\section{Co-exposure to T. gondii and SWCNT yields no novel} histological changes in the lungs as compared to mice infected with $T$. gondii or exposed to SWCNT alone To further examine the effect of a combined treatment of SWCNT and infection of $T$. gondii on the 
Table 1 Levels of cytokines, chemokines and growth factors in BAL fluid in mice exposed to SWCNT and inoculation with the parasite $T$. gondii

\begin{tabular}{|c|c|c|c|c|c|c|c|c|}
\hline \multirow{2}{*}{$\begin{array}{l}\text { Group of animals } \\
(n=6-8)\end{array}$} & \multicolumn{8}{|c|}{ Cytokine release in BAL fluid $(\mathrm{pg} / \mathrm{mL}$ ) } \\
\hline & IL-1 $\beta$ & IL-6 & IL-10 & IL-12p40 & INFY & TNFa & MCP-1 & TGF $\beta 2$ \\
\hline PBS & $55 \pm 29$ & $18 \pm 9$ & $34 \pm 12$ & $458 \pm 67$ & $45 \pm 9$ & $48 \pm 30$ & $61 \pm 37$ & $84 \pm 10$ \\
\hline SWCNT & $8 \pm 0$ & $18 \pm 7$ & $10 \pm 4$ & $1173 \pm 146$ & $25 \pm 9$ & $9 \pm 2$ & $51 \pm 22$ & $165 \pm 23$ \\
\hline T. gondii $10^{3}$ & $432 \pm 227^{*}$ & $408 \pm 136$ & $552 \pm 236^{\# *}$ & $3468 \pm 688^{\# *}$ & $5769 \pm 1799^{\# *}$ & $1016 \pm 466$ & $2569 \pm 978$ & $124 \pm 17$ \\
\hline SWCNT/ T. gondii $10^{3}$ & $165 \pm 56$ & $497 \pm 84$ & $502 \pm 108$ & $3752 \pm 292^{\# *}$ & $9090 \pm 1807^{\# *}$ & $720 \pm 199$ & $3558 \pm 745$ & $187 \pm 22$ \\
\hline T. gondii $10^{4}$ & $229 \pm 40$ & $1058 \pm 208^{\# *}$ & $612 \pm 130^{\# *}$ & $2587 \pm 409^{\#}$ & $8977 \pm 966^{\# *}$ & $859 \pm 246$ & $8214 \pm 2180^{\# *}$ & $286 \pm 58^{\# \$}$ \\
\hline SWCNT/ T. gondii $10^{4}$ & $288 \pm 51$ & $1186 \pm 387^{\# *}$ & $798 \pm 138^{\# *}$ & $2696 \pm 565^{\#}$ & $7245 \pm 1023^{\# *}$ & $1048 \pm 296^{*}$ & $11406 \pm 2167^{\# * \$ f}$ & $358 \pm 52^{\# *}$ \\
\hline
\end{tabular}

Results are presented as mean \pm SEM. Statistical significance was determined with one-way ANOVA and Bonferroni's Multiple Comparison test. \# $=\mathrm{p}<0.05$ indicates significant differences from PBS, ${ }^{*}=p<0.05$ indicates significant differences from SWCNT, $\$=p<0.05$ indicates significant differences from T. gondii $10^{3}$, and $f=\mathrm{p}<0.05$ indicates significant differences from SWCNT $+T$. gondii $10^{3}$. BAL fluid samples were obtained at 7 days post-exposure.

inflammatory response, histopathology of the lungs was performed on hematoxylin/eosin stained sections from formalin fixed specimens. The PBS control mice were unaffected and all had normal lungs. The lungs of mice exposed to only SWCNT contained variable numbers of foci of particle-laden macrophages forming distinct granulomas (Figure 3A). SWCNT-treated animals had between 0 and 33 (mean $=20.4$ ) foci of particle-laden macrophages in their lungs (Figure 4A). These foci generally originated in bronchi and bronchioles and extended into alveoli from these airways (Figure 3A). The two groups of mice infected with T. gondii alone

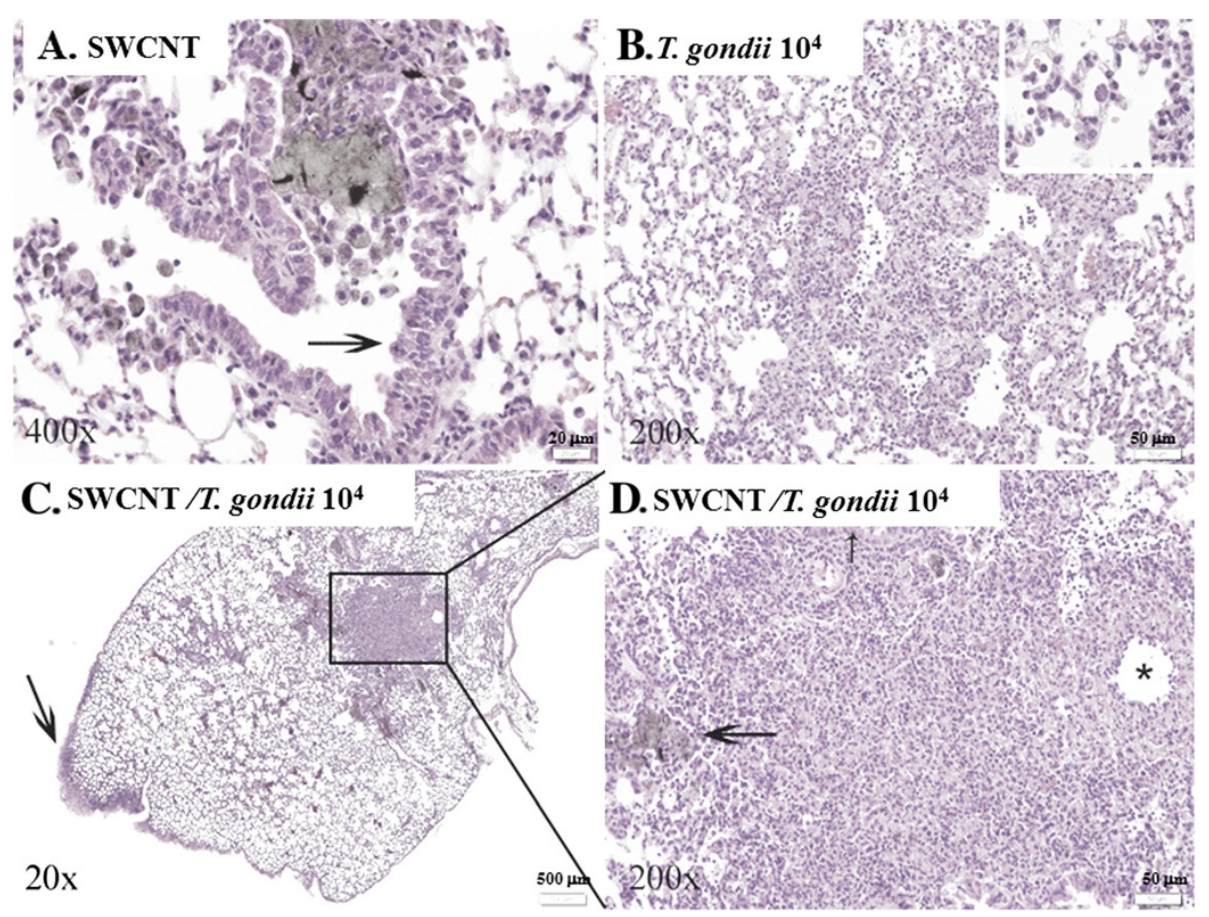

Figure 3 Pulmonary inflammation after SWCNT and/or T. gondii exposure. Representative photomicrographs of pulmonary changes in mouse lungs. A. High magnification image of an airway containing a large amount of pigmented particulate matter both free and within macrophages. The macrophages surround the material forming a small granuloma and spread out of the airway into adjacent alveoli. There is mild epithelial hyperplasia (arrow). B. High magnification view of a lung characteristic of those infected with T. gondii with loss of alveolar spaces due to pyogranulomatous inflammation and alveolar necrosis with intra-lesional protozoal vacuoles (inset). C. Lung from a mouse administered SWCNT and infected with the higher dose of T. gondii. There is focally extensive pleuritis (arrow), one large area of inflammation obliterating normal pulmonary architecture (box) and multifocal smaller nodules. D. Higher magnification view of the boxed area in (C) shows a combination of particle-laden macrophages filling airways (large arrow) and mild epithelial hyperplasia (small arrow). This is combined with vasculitis (asterisk) and necrosis with a pyogranulomatous inflammatory cell infiltrate as seen in the T. gondii infected animals. 


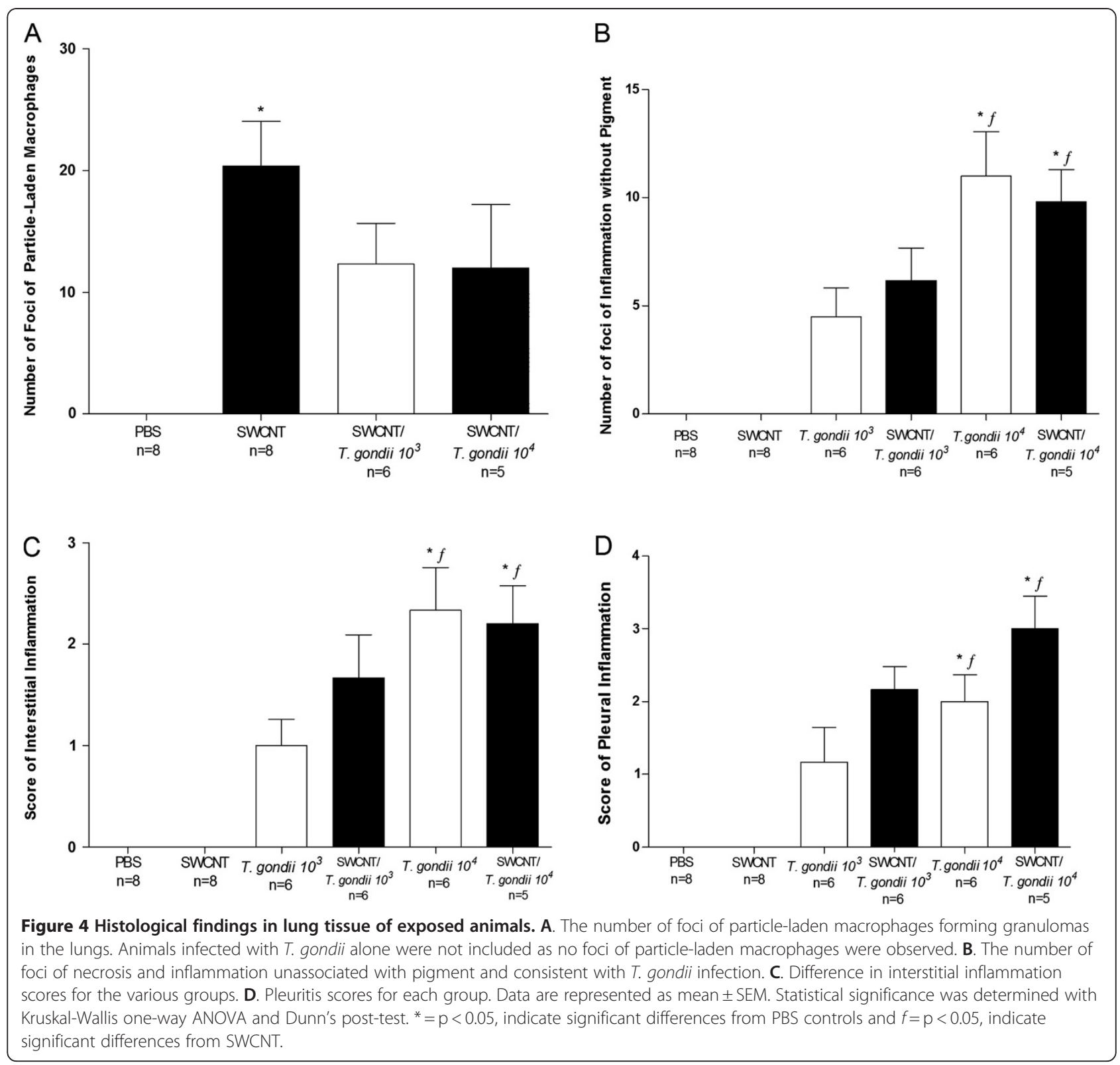

showed no evidence of granulomas as seen in the SWCNT group, but rather had multiple foci of necrotizing pyogranulomatous pneumonia (Figure 3B). Inflammation extended into the alveolar interstitium and multifocally involved the pleural surface with variable degrees of pleuritis (Figure 3B and 4B-D). Animals given higher doses of $T$. gondii organisms were more severely affected (Figure 4B-D). In animals administered both SWCNT and $T$. gondii there was a mixture of those lesions seen in the SWCNT-treated and T. gondiiinfected animals with foci of particle-associated granulomas and foci of necrotizing pneumonia (Figure $3 \mathrm{C}$ and $\mathrm{D}$ and Figure 4). For animals co-infected with the lower dose of T. gondii, animals had scores between 0 and 22 (mean $=12.3$ ). At a higher dose of $T$. gondii, animals had between 0 and 30 (mean =12) foci of particle-laden macrophages in their lungs (Figure 4A). Both SWCNT + $T$. gondii groups approached significance and a higher number of animals would likely have confirmed statistically the obvious decrease in pigmented foci. In some areas, these lesions were distinct from one another while in others they overlapped. The animals also displayed pleuritis due to the $T$. gondii infection (Figure 4D). In general, the number of necroinflammatory foci was dependent on the infectious dose of $T$. gondii and did not depend on the administration of SWCNT. While animals administered $T$. gondii and SWCNT had fewer particle-associated granulomas overall, this could 
partially be explained by larger sized lesions with fewer distinct granulomas as shown by the percent alveolar loss being markedly higher in the jointly treated groups than those administered SWCNT alone (data not shown).

When examining MPO positive neutrophils, it was clear that differences occurred between mice that were exposed to SWCNT and mice infected with $T$. gondii (Figure 5A-D). Whereas there was an extensive accumulation of neutrophils in the granulomas from mice infected with $T$. gondii, only a few neutrophils were detected in the granulomas from mice exposed only to SWCNTs. Lung sections from mice infected with T. gondii clearly showed that MPO positive neutrophils were concentrated to the more extensive granulomas, most likely as a result from T. gondii infection. When examining co-localization of MPO positive neutrophils and T. gondii, it was revealed that MPO positive neutrophils could be
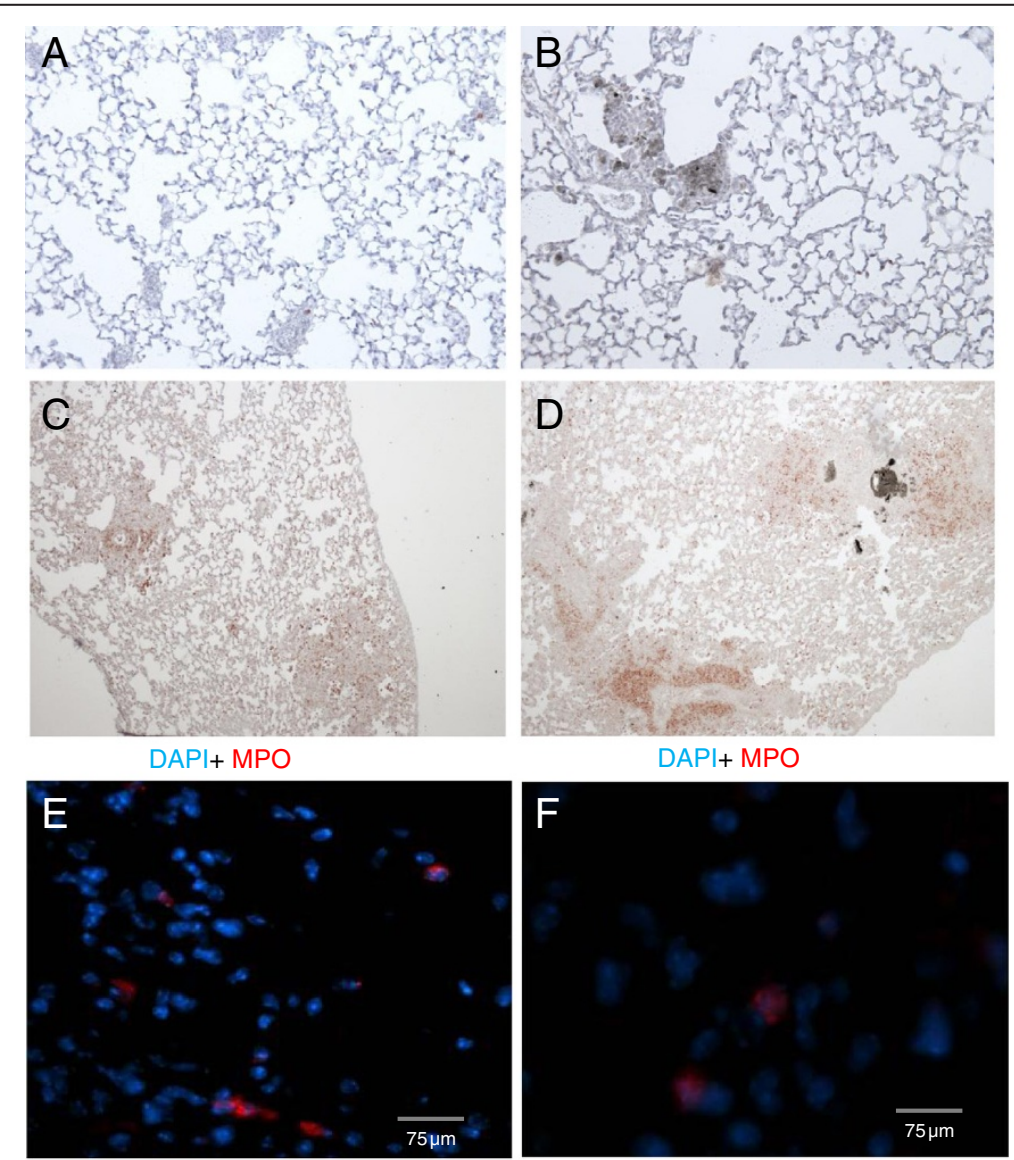

$\mathrm{DAPI}+\mathrm{T} \cdot$ gondii $+\mathrm{MPO}$

$\mathrm{DAPI}+$ T. gondii + MPO
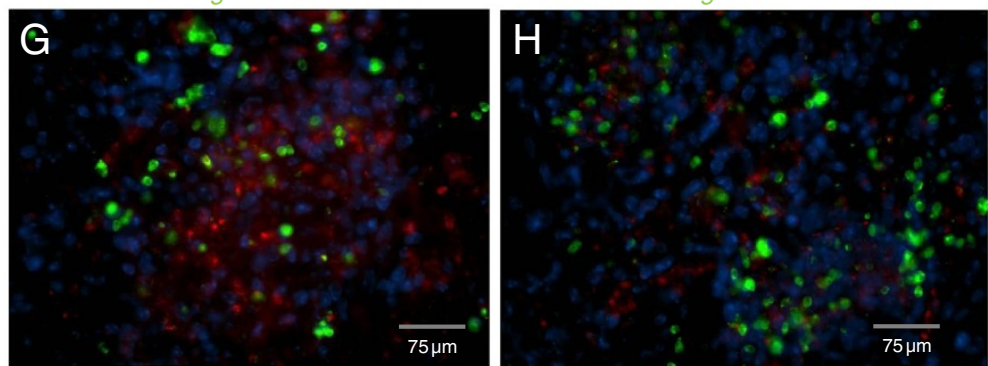

Figure 5 Co-localisation of MPO positive neutrophils and $T$. gondii in lung tissue. A-D. Histological staining of MPO positive neutrophils in lung tissue from C57BL/6 mice after exposure of SWCNT and/or T. gondii inoculation. Representative pictures of (A) PBS control, 40x magnification (B) SWCNT, 40x magnification (C) T. gondii 104, 20x magnification (D) SWCNT + T. gondii 10 20x magnification. E-H. Representative photomicrographs of fluorescence stained cells within pulmonary tissue of (E) PBS control, (F) SWCNT, (G) T. gondii 10 ${ }^{4}$, (H) SWCNT + T. gondii 10 ${ }^{4}$. Sections were mounted in medium for fluorescence including DAPI (blue). MPO positive neutrophils stained in red and T. gondii parasites stained in green in lung tissue. 
detected in neither the PBS control group nor the SWCNT exposure group (Figure 5E-H). Even though there were many more MPO positive neutrophils in the presence of $T$. gondii, there were no obvious differences between SWCNT pre-treated mice infected with $T$. gondii. The staining of MPO positive neutrophils was more intense with the higher parasite dose and the MPO staining was quite intense in the vicinity of high parasite burdens (Figure 5E-H). Parasites were present in both $T$. gondii groups (presence/absence of SWCNT), with no difference between the two T. gondii concentrations (Figure 5G-H). The presence of large intracellular vacuoles following lung section staining with anti-toxoplasma $\mathrm{Ab}$ is indicative of parasite replication (data not shown).

To study co-localization of dendritic cells and/or macrophages with SWCNT or T. gondii, double immunofluorescence staining of lung sections was performed. The SWCNT in lungs were visualized by light microscopy. The SWCNT co-localized with CD11c positive dendritic cells (DCs) in lungs of both SWCNT and SWCNT $\pm T$. gondii
A. $\quad$ SWCNT+CD11c

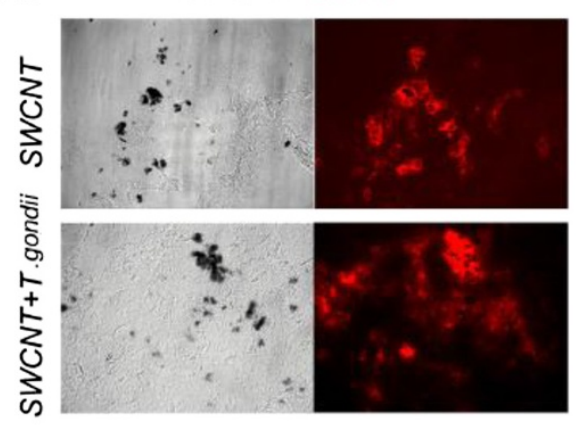

B.

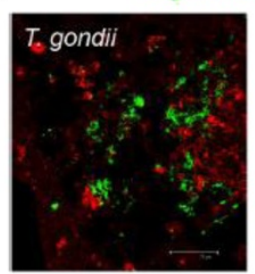

C.
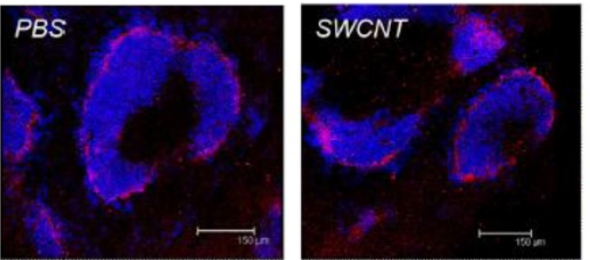

D.

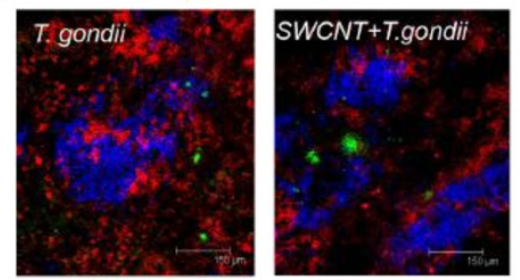

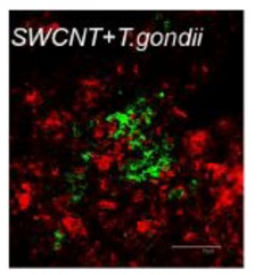

MAdCAM-1+B220
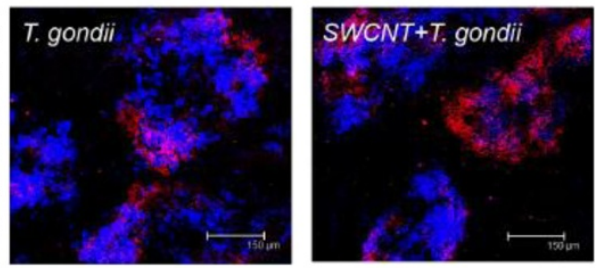

T. gondii+F4/80+B220
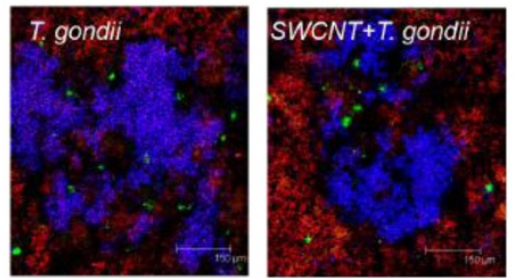

Figure 6 Co-localization of dendritic cells and/or macrophages with SWCNT or T. gondii in spleen and lung. Representative pictures of A. visualization of nanoparticles and CD11C or F4/80 positive cells in lungs of both SWCNT and SWCNT + T. gondii $10^{4}$ treated mice. 40x magnification B. Double staining with anti-toxoplasma Ab and anti-CD11c or anti-F4/80 mAb in lungs of both SWCNT and SWCNT + T. gondii 10 4 treated mice. C. MAdCAM-1 and B-cell staining (B220) in frozen spleen sections. D. Triple staining with anti-toxoplasma, anti-B220 and anti-CD11C or anti-F4/80 in frozen spleen sections. 
treated mice, indicating that $\mathrm{CD} 11 \mathrm{c}$ positive $\mathrm{DCs}$ can engulf the SWCNT (Figure 6A); however, the particles did not co-localize with F4/80 positive cells (macrophages). The F4/80 positive macrophages accumulated around the SWCNT and participated in the formation of granuloma. Double staining with anti-toxoplasma $\mathrm{Ab}$ and anti-CD11c or anti-F4/80 mAb showed that the CD11c and F4/80 positive cells did not co-localize with $T$. gondii in lungs from mice irrespective of SWCNT pre-treatment (Figure 6B).

To further study lung pathology, PAS staining was performed to assess mucin-containing goblet cells. There was a slight increase in the number of goblet cells in mice challenged with SWCNTs based on representative lung sections whereas hardly any goblet cells were detected in control mice or mice infected with $T$. gondii (data not shown).

\section{Pre-exposure to SWCNT did not affect the splenocyte} response to $T$. gondii localized in both the follicle and red pulp of spleen

To investigate systemic effects of SWCNT on T. gondii infection, spleen tissue were examined. MAdCAM-1 staining was used to show the marginal sinus structure of spleen, which separates the follicle (inside) and redpulp (outside). Double immunofluorescence staining showed that toxoplasma infection impaired the structure of the spleen. The marginal sinus and follicles in $T$. gondii infected mice showed a defective structure compared with mice receiving PBS or SWCNT (Figure 6C). Triple staining with anti-toxoplasma, anti-B220 (B cell marker) and anti-CD11c or anti-F4/80 showed that $T$. gondii localized in both the follicle and red pulp of spleen; no co-localization (double staining) was seen with anti-toxoplasma and anti-CD11c or anti-F4/80
mAb (Figure 6D). Furthermore, there was no colocalization between the MARCO (scavenger receptor) positive macrophage population and $T$. gondii or SWCNT (data not shown).

Splenocytes from PBS control mice and mice exposed to only SWCNT showed an increased proliferation to ConA, but did not respond to the $T$. gondii antigen as expected (Figure 7). However, spleen cells from mice exposed to $T$. gondii with or without pre-exposure to SWCNT demonstrated a decrease in cell proliferation after ConA and T. gondii antigen stimulation (Figure 7). The quality of the $T$. gondii antigen was confirmed with the release of IFN- $\gamma$ into the cell culture medium of single cell suspensions from spleens of $T$. gondii infected mice (See Additional file 1; [19]).

\section{Discussion}

It has been previously reported that pulmonary exposure to SWCNT induced robust inflammation, early granulomatous lesions and interstitial fibrosis in the lungs of mice [2,3]. The histological data obtained from the current study exposing mice to respirable SWCNT are very consistent with the previously reported (Figure 4). Notably, the architecture of mouse lungs after exposures to SWCNT and SWCNT $+T$. gondii groups demonstrated an increase in pigmented foci after exposure to SWCNT and SWCNT $+T$. gondii. No granulomatous lesions were observed in lungs of mice treated with $T$. gondii. There were also no differences in severity of granulomatous lesions seen in SWCNT and SWCNT + T. gondii exposure groups. Several recent reports indicated that SWCNT exposure was able to modify outcomes to infectious agents. In particular, it was demonstrated that sequential exposure to SWCNT and

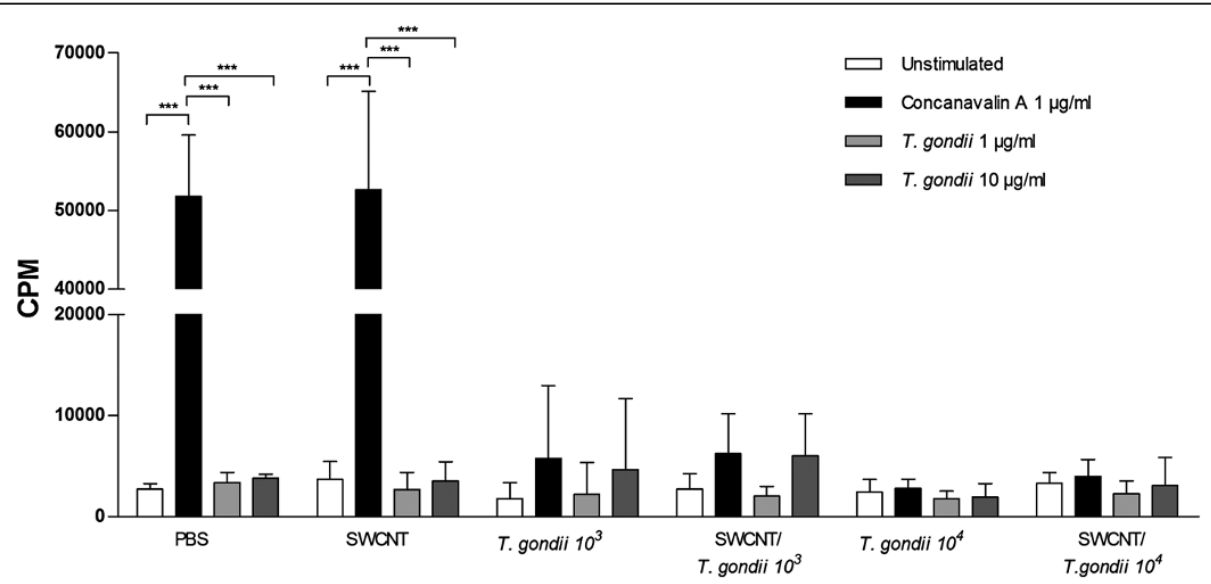

Figure 7 Impaired immune response after $T$. gondii exposure. Single cell suspensions from spleens from mice exposed to SWCNT and/or T. gondii in two doses $\left(10^{3}\right.$ or $10^{4}$ parasites) were cultured for $66 \mathrm{~h}$ with or without ConA $(1 \mu \mathrm{g} / \mathrm{ml})$ or $T$. gondii antigen $(1 \mathrm{or} 10 \mu \mathrm{g} / \mathrm{ml}){ }^{3}[\mathrm{H}]-$ Thymidine was added during the last $18 \mathrm{~h}$ and incorporation was determined by scintillation counting. Results are expressed as mean counts per minute $(\mathrm{cpm})$ from six mice/group \pm SD. Level of significance ${ }^{* * *} \mathrm{p}<0.001$ determined with two-way ANOVA, and Bonferroni's Multiple Comparison test. 
L. monocytogenes (LM) amplified lung inflammation and collagen deposition in mouse lungs [2]. The pulmonary clearance of LM from the lungs of SWCNT pre-exposed animals was markedly delayed. The reduced ability of macrophages to phagocytose LM in the presence of SWCNT was found to be related to a reduction of macrophage production of nitric oxide in response to LM [2]. However, it has to be emphasized that in the LM + SWCNT study, both agents were concomitantly administered to mice via aspiration route. While T. gondii can elicit pathology in the pulmonary tissues [9-11], inhalation is not the natural route of access. During natural infections or reactivated acute infection, the parasite reaches the lung tissue through the systemic circulation. In contrast with the administration route from the LM study, we infected our mice intravenously with $T$. gondii, providing widespread haematogenic dissemination of parasites and enhanced parasite infection in the lungs compared to other administration routes [17]. Even with enhanced parasite migration, the lungs allowed for a better assessment of parasite replication as opposed to other organs such as the spleen, where replication is usually much more extensive. Thus, despite haematogenous access of parasites to lung tissue, the parasitic loads in SWCNT-exposed mice were not significantly higher compared to untreated mice. To this end, our current data have revealed that the progression of an initially generalized $T$. gondii infection was not significantly modified by an acute pulmonary response to respirable SWCNT administrated prior to the infection. Reciprocal approaches have shown that immune responses to $T$. gondii can mediate protective effects on concomitant inflammatory conditions in the lungs [20-22] and are indicative of the complexity of the immune response. In contrast, the experimental protocol applied here assessed whether the host response following pharyngeal aspiration of SWCNT affects T. gondii infection. In our study, pre-exposure to SWCNT did not enhance or suppress the early immune response to $T$. gondii in mice. Rather, the absence of accentuated pathology in the lungs indicates that the deposition of SWCNT in the lung tissue may have a different impact on immune responses depending on the route of access for the pathogens, with a relatively minor impact on haematogenously spread infection compared to airway exposure.

The selected dose range for exposure to respirable SWCNT $(160 \mu \mathrm{g} /$ mouse) in the current study was based on previously found immune suppression reported in mice [20]. The calculated exposure levels in this study are relevant to those found in actual workplace conditions and, are in fact lower than those levels that could be achieved during life-time work exposures [23]. The cumulative SWCNT doses we used were given to mice on day 1 and 2 and T. gondii was administered on day 3 .
However, further investigations are warranted to determine whether prolonged pre-exposure to SWCNT would have a more discernible impact on the establishment and development of $T$. gondii infection in vivo.

Several lines of evidence suggest that migrating DC play a critical role during $T$. gondii infection as systemic carriers of $T$. gondii tachyzoites [14,16,24,25]. In addition, DCs function as both antigen-presenting cells as well as the main source of IL-12 and TNF- $\alpha$ in response to $T$. gondii antigens [26]. IL-12 induces early IFN- $\gamma$ production in NK cells and facilitates subsequent Th1 development, whereas TNF- $\alpha$ is involved in mediating resistance to acute and chronic T. gondii infections [27-30]. Infection with $T$. gondii did not give any immediate sign of unhealthyness but there was a significant weight loss by day 10 in the $T$. gondii infected mice without any differences related to whether mice had been pre-exposed to SWCNT or not (See Additional file 2). Our measurements of inflammatory mediators in BAL fluid showed that there were some increases in several mediators measured after T. gondii infection, albeit not statistically significant when compared to PBS controls and mice exposed to SWCNT only. Furthermore, there was no clear difference following co-exposure to SWCNT and $T$. gondii. Exposure to SWCNT alone induced no changes in the levels of mediators in BAL fluid. Hence, while it has been clearly established that infection with $T$. gondii results in interplay between the parasite and the host [31], resulting in a complex cascade of pro- and antiinflammatory responses [32], we could not reveal any effects of SWCNT exposure on the parasite-induced responses.

Notably, we have recently found that SWCNT-induced inflammation facilitated the recruitment of DCs to the lung and redistribution of DCs to lymphoid tissues [23]. In the present study, nanoparticles co-localized with CD11c positive DCs in lungs of both SWCNT and SWCNT $\pm T$. gondii treated mice, however, they did not co-localize with F4/80 positive cells (macrophages), indicating that $\mathrm{CD} 11 \mathrm{c}$ positive DC interact with the particles. We have previously shown uptake of SWCNT by DCs in vitro using murine DCs generated from hematopoietic progenitors isolated from bone marrow [23]. Our finding here on the in vivo uptake of SWCNT in the lung by CD11c positive DCs but not by F40/80 positive macrophages is to our knowledge novel data. Moreover, previous findings $[28,33]$ indicate that infected DCs are compromised in their ability to activate $\mathrm{T}$ cells, suggesting that the arrival of infected DCs in lymphoid tissues will not result in efficient priming of a $\mathrm{T}$ cell response. In our recent study, direct effects of SWCNT on DCs resulted in suppressed spleen T cell responses upon pulmonary exposure [23]. Pulmonary exposure to multi-walled carbon nanotubes (MWCNT) 
was also reported to suppress spleen cells responses to mitogen stimulation $(17,18)$. In the current study, we observed even greater suppression of splenocyte proliferation in all groups infected with $T$. gondii, which has been described previously [19]. In addition, it was found that $T$. gondii was not taken up by the macrophage (F4/80 or MARCO positive) or DCs (CD11c positive) populations in the spleen. Unfortunately, the data for SWCNT was not conclusive since the spleen is filtering red blood cells resulting in iron deposits thus making it impossible to specifically detect the nanoparticles using light microscope. It remains to be investigated which population of cells respond to $T$. gondii infection and produce IFN $\gamma$ in the spleen. However, there was no evidence of any modulatory effect on $T$. gondii proliferation or dissemination in the host in the presence of SWCNT in the current model.

As expected, the lungs of mice exposed to only SWCNT contained variable numbers of foci of particleladen macrophages forming distinct granulomas. The two groups of mice infected with $T$. gondii alone showed no evidence of granulomas; instead, multiple foci of necrotizing pyogranulomatous pneumonia were found in the lung, and mice receiving higher doses of $T$. gondii organisms were more severely affected. The co-exposure to T. gondii and SWCNT appeared to yield a mixture of histological changes in the lung with foci of particleassociated granulomas as well as foci of necrotizing pneumonia. In general, however, the number of necroinflammatory foci was dependent on the infectious dose of T. gondii and did not depend on the administration of SWCNT. In addition, the increased numbers of neutrophils were a result of inoculation of $T$. gondii rather than SWCNT exposure, whereas CD11c positive DC colocalized with SWCNT exposure possibly due to engulfment of the particles.

\section{Conclusions}

In synopsis, the current analysis of infection parasite distribution and parasite burden using non-invasive BLI as well as plaquing assays shows that administration of SWCNT via pharyngeal aspiration prior to infection with $T$. gondii has no discernable effect on the establishment, dissemination, and proliferation of infection. This, however, does not preclude the possibility that exposure to SWCNT may affect the establishment of the chronic phase of infection. Further studies are warranted to address this question. In conclusion, our data suggest that exposure to SCWNT does not affect the early immune response against $T$. gondii.

\section{Materials and methods}

Animals and parasites

Female C57BL/6 mice (6-8 weeks of age) were purchased from Charles River (Sulzfeld, Germany) and maintained under pathogen-free conditions at the Swedish Institute for Communicable Disease Control animal facility (The animals were housed in ventilated filtered plastic cages with absorbent bedding material and were maintained on a $12 \mathrm{~h}$ daylight cycle). Food and water were provided ad libitum. All animal experiments were approved by the regional committee of animal experimentation ethics (Dnr: N15/11; Stockholm North ethical committee for animal welfare, Stockholm, Sweden).

Tachyzoites from the green fluorescence protein (GFP) and luciferase-expressing $T$. gondii type II line PTGluc (cloned from ME49/PTG-GFPS65T) [17] were maintained by serial 2-days passage in human foreskin fibroblast (HFF) monolayers. HFFs were propagated in Dulbecco's modified Eagle's medium (DMEM; Invitrogen, Carlsbad, CA, USA) with $10 \%$ fetal bovine serum (FBS), gentamicin $(20 \mu \mathrm{g} / \mathrm{ml}$, Gibco), glutamine $(2 \mathrm{mM}$, Gibco) and Hepes (0.01 M, Gibco).

\section{Single walled carbon nanotubes}

SWCNT (CNI, Houston, TX) produced by the highpressure $\mathrm{CO}$ disproportionation (HiPco) process, employing $\mathrm{CO}$ in a continuous-flow gas phase as the carbon feedstock and $\mathrm{Fe}(\mathrm{CO})_{5}$ as the iron-containing catalyst precursor and purified by acid treatment to remove metal contaminants were used in the study. Morphology of the SWCNT is presented in Figure 8 and the detailed characterization of the utilized SWCNT is provided elsewhere [23]. Stock suspensions $(1 \mathrm{mg} / \mathrm{ml})$ were prepared before each experiment in PBS or culture medium and $\mathrm{pH}$ was adjusted to 7.0. Endotoxin content in SWCNT samples was assessed using the Limulus amebocyte lysate (LAL) enzyme assay (DataChem Inc, Salt Lake City, UT). The endotoxin content of SWCNT suspensions was lower than $0.11 \mathrm{EU} / \mathrm{ml}$. The amount of endotoxin received by mice was $0.006 \mathrm{EU}$, a dose equivalent to $0.6 \mathrm{pg}$ endotoxin. A similar level of endotoxin was found in the vehicle (pharmaceutical grade). To obtain a more homogenous and dispersed suspension, SWCNT were ultrasonicated (30 sec $\times 3$ cycles). Scanning electron microscopy of the samples showed that sonication resulted in the production of well-dispersed SWCNT (Figure 8B).

\section{Experimental design}

The study was divided into two separate experiments starting on two consecutive days. Mouse pharyngeal administration was used for instillation of the SWCNT particles. Briefly, after anesthetization with a mixture of ketamine and xylazine (62.5 and $2.5 \mathrm{mg} / \mathrm{kg}$, respectively), the mouse was placed on a board in a near vertical position and the tongue was extended with forceps. A suspension of $40 \mu \mathrm{l}$ particles in PBS was placed in the throat, and the tongue held until the suspension was 

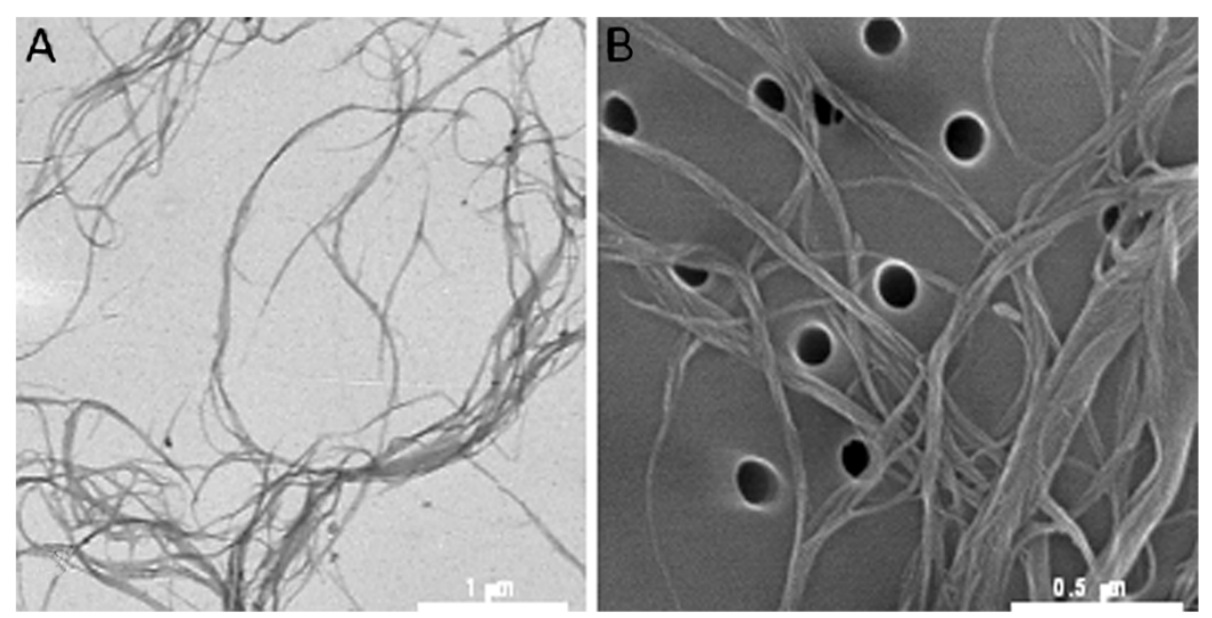

Figure 8 Particle characterization. A. Transmission electron microscopy (TEM) image of individual SWCNT confirmed a length of approximately 1-3 $\mu \mathrm{m}$; B. Scanning electron microscopy (SEM) of the samples showed that sonication resulted in the production of well-dispersed SWCNT.

aspirated into the lungs. A total dose of $160 \mu \mathrm{g} /$ mouse $(80+80 \mu \mathrm{g})$ or PBS was aspirated on day 1 and 2 . At day 3 , the mice were infected intravenously in the tail with either $1 \times 10^{3}$ or $1 \times 10^{4}$ freshly egressed tachyzoites resuspended in $200 \mu \mathrm{l}$ PBS (PTG-GFPluc). Control mice were injected intravenously in the tail with $200 \mu \mathrm{l}$ PBS only. The six experimental groups ( $\mathrm{n}=6-8$ per group) were: PBSanimals pre-treated and injected with PBS; SWCNTanimals pre-treated with $160 \mu \mathrm{g}$ SWCNT and injected with PBS; T. gondii $10^{3}$-infected animals pre-treated with PBS; SWCNT $+T$. gondii $10^{3}$-infected animals pre-treated with $160 \mu \mathrm{g}$ SWCNT; T. gondii $10^{4}$ infected animals pre-treated with PBS; and SWCNT + T. gondii $10^{4}$-infected animals pre-treated with $160 \mu \mathrm{g}$ SWCNT. On day 10, the weight of the animals was assessed. Thereafter, the animals were sacrificed immediately whilst under anaesthesia via cervical dislocation, bronchoalveolar lavage (BAL) was performed, followed by dissection of the spleen and lungs.

\section{In vivo bioluminescence imaging (BLI)}

BLI was performed 2, 4, 6 and 7 days after $T$. gondii injection, as described previously [17]. Briefly, mice were injected i.p. with $3 \mathrm{mg}$ D-luciferin potassium salt (Caliper Life Sciences, Hopkinton, MA, USA) and anaesthetized with $2.3 \%$ isoflurane prior to BLI. Ten min after injection of D-luciferin, biophotonic images were acquired at a binning of 8 (medium) for $300 \mathrm{~s}$ with an In Vivo Imaging System Spectrum (IVIS Spectrum Caliper Life Sciences, Hopkinton, MA, USA). Analysis of images and assessment of photons emitted from a region of interest (ROI) was performed with Living Image software (version 3.2; Caliper Life Sciences, Hopkinton, MA, USA).

\section{Bronchoalveolar lavage (BAL)}

BAL was performed after IVIS measurements on day 10 . A total volume of $1 \mathrm{ml}$ PBS was used to lavage the lungs via trachea, by using a prefilled $1 \mathrm{ml}$ syringe which was inflated and aspirated three times with the same fluid. When required, red blood cells were removed by resuspending the BAL fluid cells in $100 \mu \mathrm{l}$ lysis buffer $\left(150 \mathrm{mM} \mathrm{NH} \mathrm{N}_{4} \mathrm{Cl}, 10 \mathrm{mM} \mathrm{KHCO} 3,0.1 \mathrm{mM}\right.$ EDTA, pH 7.2) for $2 \mathrm{~min}$ at RT followed by washing in $1 \mathrm{ml}$ PBS. The total number of cells was then counted and adjusted to cells $\cdot \mathrm{ml}^{-1}$ BAL fluid. For differential cell counts, cells were stained with May Grünwald-Giemsa and a minimum of 300 cells were counted per BAL fluid sample.

\section{Protein concentration}

The total protein concentration in BAL fluid was measured with the BioRad DC protein assay (BioRad Life Science Research, Hercules, CA, USA) according to manufacturer's instruction. Triplicate of samples were read at $650 \mathrm{~nm}$ using a Spectrophotometer (Multiskan Ascent, Thermo Scientific, Waltham, MA, USA). Results are presented as $\%$ of control treated mice \pm SD.

\section{Lactate dehydrogenase (LDH)}

To determine the release of LDH in BAL fluid, the CytoTox $96^{\circledR}$ Non-Radioactive Cytotoxicity Assay (Promega Corporation, Madison, WI, USA) was used. Triplicates of BAL fluid aliquots $(50 \mu \mathrm{l}, 2$ times diluted in PBS) was transferred to a 96-well flat bottom plate. Assay buffer and substrate was mixed according to manufacturer's instruction to constitute Substrate mix. $50 \mu \mathrm{l}$ of Substrate mix was added to all wells and the plate was incubated in dark in a humidified atmosphere at $37^{\circ} \mathrm{C}$. After $30 \mathrm{~min}$ incubation, $50 \mu \mathrm{l}$ of stop solution was added to all wells and the absorbance was recorded at $492 \mathrm{~nm}$ using a Spectrophotometer (Multiskan Ascent, Thermo 
Scientific, Waltham, MA, USA). Results are presented as $\%$ of control treated mice \pm SD.

\section{Plaquing assays}

Directly after BAL was done on day 10, the lungs and spleens were extracted. Organ homogenization (half of the spleen and one lobe on the right side of the lung) was performed under conditions that did not affect parasite viability [34]. The number of viable parasites was determined by plaque formation on human foreskin fibroblast monolayers as described [34].

\section{Measurement of released mediators in BAL fluid}

The levels of selected cytokines/chemokines and growth factors were measured in duplicates in BAL fluid using a mouse plex-assay (BioRad, Hercules, CA, USA) and assayed by Luminex ${ }^{\circledR}$ (BioRad, Hercules, CA, USA). Labelled antibodies against IL-1 $\beta$, IL-6, IL-10, IL-12p40, MCP-1, IFN- $\gamma$ TNF- $\alpha$ and TGF- $\beta 1-3$ were used for analyses of multiple cytokine responses according to provided instructions. Results below the detection limits were set as the absolute threshold for statistical evaluation.

\section{Lung histology}

Left lung was inflated with $4 \%$ formalin (Sigma-Aldrich, St. Louis, MO, USA) at a pressure of $20 \mathrm{cmH}_{2} \mathrm{O}$ and fixed for $24 \mathrm{~h}$. Five $\mu \mathrm{m}$-thick lung sections were cut and assessed with hematoxylin and eosin to evaluate the extent of cellular infiltration in the lung tissue. Slides (one section per lung, several fields of view for each slide to secure the conclusions) were examined under non-coded conditions and were assessed for histopathologic changes. Bronchiolar epithelial hyperplasia was scored on a scale from $0-5$, where $0=$ no change and $5=$ severe change. The number of foci of particle-laden macrophages were counted in the samples. For animals infected with $T$. gondii, the number of necroinflammatory foci were counted, the degree of bronchiolar hyperplasia, pleuritis, and the amount of interstitial inflammation were scored on a scale of $0-5$ as above. For animals infected with T. gondii and administered SWCNT, a combination of findings were recorded including counts of the number of foci of particle-laden macrophages, necroinflammatory foci and scores for bronchiolar hyperplasia, pleuritis, and interstitial inflammation. In addition, slides were stained with periodic acid-Shiffs staining (Sigma-Aldrich, St. Louis, MO, USA) to assess mucin-containing goblet cells.

\section{Immunohistochemical stainings of lung and spleen}

Immunohistochemical staining for detection of $T$. gondii and neutrophils (myeloperoxidase, MPO) on the formalin fixed lung sections was performed. Initially, lung sections were hydrated with tap water, followed by antigen retrieval, pretreatment of $3 \%$ hydrogen peroxide and $2.5 \%$ normal horse serum (Vector Labs, Burlingame, CA, USA) to block nonspecific reactivity. Sections were incubated with rabbit-anti-mouse MPO (ab9535, AbCam, Cambridge, UK; $1: 100,4^{\circ} \mathrm{C}$ overnight) and with a peroxidase conjugated anti-rabbit as secondary antibody (ImmPRESS, MP-7401, Vector labs, Burlingame, CA, USA; $30 \mathrm{~min}$, RT). After washing, color was developed by adding AEC (3-amino-9-ethylcarbazole) chromogen for $10 \mathrm{~min}$ (SK4200, Vector Labs, Burlingame, CA, USA). Finally, slides were counterstained with hematoxylin and mounted using faramount (DAKO, Glostrup, Denmark). Negative control sections were treated in the same way but primary antibodies were omitted. Sections were also doublestained with rabbit-anti-mouse MPO (ab9535, AbCam, Cambridge, UK; $1: 100,4^{\circ} \mathrm{C}$ ON) primary antibody and primary human-polyclonal anti- $T$. gondii antibodies (1:500, WHO's standard, Statens Serum Institute, Copenhagen, Denmark) followed by a secondary anti-rabbit Alexa 594 (1:400, Molecular Probes, Eugene, OR, USA) and Alexa Fluor 488 goat anti-human IgG (1:400, Molecular Probes, Eugene, OR, USA), respectively, to detect co-localization of MPO positive neutrophils and parasites. Sections were mounted in medium for fluorescence including DAPI (Vector labs, Burlingame, CA, USA). Stained sections were examined using light microscope and images were capture at 20x or higher magnifications.

In addition, $8 \mu \mathrm{m}$ thin cryosections of snap frozen spleen or lung specimens were fixed in acetone. After blocking with goat serum (DAKO, Glostrup, Danmark) and avidin/biotin blocking kit (Vector labs, Burlingame, CA, USA), sections were incubated with primary $\mathrm{Ab}$, followed by several washes in PBS and incubation with fluorescently-labelled secondary Abs or Alexa-555conjugated streptavidin (Molecular Probes, Eugene, OR, USA). The following Abs were used: anti-mouse F4/80 (CI:A3-1, rat IgG2b, AbD Serotec, Oxford, UK); biotin conjugated anti-mouse.

CD11c (HL3, hamster IgG1, BD biosciences, San Jose, CA, USA), visualized by Alexa-555-streptavidin (Invitrogen, California, USA); anti-toxoplasma (WHO's standard, Statens Serum Institute), anti-mouse MARCO (ED31, rat IgG1, AbD Serotec, Oxford, UK), Alexa-488conjugated goat anti-human IgG (Molecular Probes, Eugene, OR, USA) Alexa-555-conjugated goat anti-rat IgG (Molecular Probes, Eugene, OR, USA). Stainings with isotype controls were performed to confirm the specificity of the immunostainings. Images were acquired using a confocal laser scanning microscope (TCS SP2; Leica Microsystems, Mannheim, Germany) or Leica application suite (Leica Microsystems).

\section{Splenocyte culture and proliferation}

Spleen samples (one third of the spleen) were collected in complete medium consisting of RPMI 1640 medium 
(Sigma Aldrich, St. Louise, MO) supplemented with $2 \mathrm{mmol} / \mathrm{L}$ L-glutamine, $100 \mathrm{IU} / \mathrm{ml}$ penicillin, $100 \mu \mathrm{g} /$ $\mathrm{ml}$ streptomycin (Gibco Invitrogen Corporation, California USA), $50 \mu \mathrm{M}$-mercaptoethanol (KEBO-lab, Spånga, Sweden), and 10\% heat inactivated fetal calf serum (HyClone SH30071.03, Thermo Scientific, Waltham, MA, USA) and kept on ice until processing. The spleens were processed individually by gentle mashing with a plunger of a $5 \mathrm{ml}$ syringe in $2 \mathrm{ml}$ complete medium on a $70 \mu \mathrm{m}$ cell strainer on a Petri dish. After washing the plunger and the cell strainer with $3 \mathrm{ml}$ additional medium, the cell suspension was transferred to a Falcon tube and centrifuged for $10 \mathrm{~min}$ at $300 \mathrm{~g}$ at room temperature. The supernatant was discarded and the cell pellet was resuspended in $1 \mathrm{ml}$ ACK lysis buffer for $1 \mathrm{~min}(0,15 \mathrm{M}$ $\mathrm{NH}_{4} \mathrm{Cl}, 10 \mathrm{mM} \mathrm{KHCO}_{3}, 0,1 \mathrm{mM} \mathrm{Na}_{2}$ EDTA, pH adjusted to 7.4). Following red blood cell lysis, the remaining cells were washed once with complete medium at $300 \mathrm{~g}$ for $10 \mathrm{~min}$ and kept on ice until further processing. The cells were counted with trypan blue exclusion and the cell viability was $87.4 \pm 3.7 \% . \quad(n=36) .200 \mu \mathrm{l} \quad$ of cell suspension $\left(2 \times 10^{5}\right.$ viable cells $) /$ well was placed in a round bottom 96 well plate in triplicates with or without stimuli; Concanavalin A (ConA) $1 \mu \mathrm{g} / \mathrm{ml}$ or $T$. gondii antigen 1 or $10 \mu \mathrm{g} / \mathrm{ml}$ made in house [35]. After $48 \mathrm{~h}$ or $72 \mathrm{~h}, 1 \mu \mathrm{Ci}{ }^{3}[\mathrm{H}]$-thymidine (Amersham, Buckinghamshire, UK) was added to each well for additional $18 \mathrm{~h}$ where after the thymidine incorporation was determined by scintillation counting. Results are expressed as mean counts per minute $(\mathrm{cpm}) \pm \mathrm{SD}$.

\section{IFN- $\gamma$ ELISA}

IFN- $\gamma$ levels were determined in cell culture supernatants from the splenocyte proliferation study using a mouse IFN- $\gamma$ ELISA kit from MabTech (Nacka Strand, Sweden) according to manufacturer's instructions. Results are presented as mean $\mathrm{pg} / \mathrm{mL} \pm \mathrm{SD}$ of triplicates.

\section{Statistical analysis}

Differences among the treatment groups were assessed by oneway or two-way analysis of variance (ANOVA). Significant ANOVAs were further analysed using Bonferroni, Tukeys pairwise comparison, Dunn's post hoc test or Kruskal-Wallis test using Gaussian approximation. A p-value of less than 0.05 was considered significant. Statistical analysis and graphs were performed in Graph Pad Prism (version 5.0 GraphPad software Inc., San Diego, CA, USA) and Minitab version 15 (Minitab Inc, PA, USA).

\section{Additional files}

\begin{abstract}
Additional file 1: Increased IFN- $\gamma$ production in $T$. gondii infected mice. Single cell suspensions of spleens from mice exposed to PBS or $T$. gondii in two doses ( $10^{3}$ or $10^{4}$ parasites) were cultured for $48 \mathrm{~h}$ with or without ConA $(1 \mu \mathrm{g} / \mathrm{ml})$ or $T$. gondii antigen ( 1 or $10 \mu \mathrm{g} / \mathrm{ml})$. Thereafter the culture supernatants were subjected to IFN- $\gamma$ ELISA. Results are presented as mean IFN- $\gamma \mathrm{pg} / \mathrm{mL} \pm \mathrm{SD}$ from triplicates of six-eight mice divided on two experiments. Level of significance * $p<0.05$, ${ }^{* *} p<0.01$ and ${ }^{* * *} p<0.001$ determined with two-way ANOVA, and Bonferroni's Multiple Comparison test.
\end{abstract}

Additional file 2: Weight loss in mice after $T$. gondii infection. The weight of mice was measured on day 10. Data are presented as mean \pm SEM. Statistical significance was determined with one-way ANOVA and Bonferroni's Multiple Comparison test. ${ }^{*}=p<0.05$ compared to PBS controls, $f=p<0.05$ compared to SWCNT.

\section{Abbreviations}

ANOVA: Analysis of variance; BAL: Bronchoalveolar lavage;

BLI: Bioluminescense imaging; CNT: Carbon nanotubes; DC: Dendritic cells; DMEM: Dulbecco's modified eagle's medium; ELISA: Enzyme-linked immunosorbent assay; FBS: Fetal bovine serum; HFF: Human foreskin fibroblast; IL: Interleukin; INF: Interferon; IVIS: In vivo imaging system spectrum; LAL: Limulus amebocyte lysate; LDH: Lactate dehydrogenase; LM: Listeria monocytogenes; MCP-1: Monocyte chemoattractant protein-1; MPO: Myeloperoxidase; MWCNT: Multi-walled carbon nanotubes;

PBS: Phosphate buffered saline; ROI: Region of interest; SEM: Standard error of the mean; SWCNT: Single-walled carbon nanotubes; TGF: Transforming growth factor; TNF-a: Tumor necrosis factor-alpha; T. gondii: Toxoplasma gondii.

\section{Competing interests}

The authors declare that they have no competing interest.

\section{Authors' contributions}

LS participated in the study design, conducted the animal exposure studies, data analysis, the Luminex assay, performed differential cell counts, immunohistochemistry and lung histology; RA participated in the study design, conducted the animal exposure studies, data analysis, and performed bioluminescence imaging and plaquing assays; BA-W measured total protein and LDH levels in BAL fluid, and performed the splenocyte cultures and ELISA analysis; AM conducted the animal exposure to SWCNT; YC and MK performed immunohistology analysis on lung and spleen specimens; SKG conducted part of the Luminex assay, advised and assisted on histological methods and performance; AVT analysed data; AAS, BF, AB, AS designed the animal study; AS coordinated the study and data analysis and the first version of the manuscript together with LS and RA. All authors have contributed to draft the manuscript and have read and approved the final manuscript.

\section{Authors' information}

Dr Bengt Fadeel, Dr Anna A Shvedova, Dr Antonio Barragan, and Dr Annika Scheynius share the senior authorship.

\section{Disclaimers}

The findings and conclusions in this report are those of the authors and do not necessarily represent the view of the National Institute for Occupational Safety and Health.

\section{Acknowledgements}

This work was supported by the Seventh Framework Programme of the European Commission (EC-FP7-NANOMMUNE-Grant Agreement No. 214281), NIOSH NTRC \#1927ZJHF, the Swedish Research Council, the Swedish Council for Working Life and Social Research, and Karolinska Institutet. We are grateful to Lisa Sjöberg, and Cecilia Kemi (Karolinska Institutet) for excellent advice and assistance on histological methods and to Prof. Sven-Erik Dahlén (Karolinska Institutet) for valuable comments. The authors are thankful to Joshua Kramer D.V.M at Charter Preclinical Services, Hudson, MA, USA, for pathological examination of hematoxylin and eosin stained lung preparations. 


\section{Author details}

'Institute of Environmental Medicine, Division of Molecular Toxicology, Karolinska Institutet, Stockholm, Sweden. ${ }^{2}$ Swedish Institute for Communicable Disease Control, Stockholm, Sweden. ${ }^{3}$ Center for Infectious Medicine, Department of Medicine, Karolinska Institutet, Stockholm, Sweden. ${ }^{4}$ Translational Immunology Unit, Department of Medicine Solna, Karolinska Institutet, Stockholm, Sweden. ${ }^{5}$ Pathology and Physiology Research Branch, Health Effects Laboratory Division, National Institute for Occupational Safety and Health, Center for Disease Control and Prevention, Morgantown, WW, USA. ${ }^{6}$ Department of Clinical Science, Intervention and Technology, Division of ENTdiseases, Karolinska Institutet, Stockholm, Sweden. 'Department Physiology and Pharmacology, School of Medicine, West Virginia University, Morgantown, WV, USA.

Received: 7 March 2012 Accepted: 5 May 2012 Published: 23 May 2012

\section{References}

1. Shvedova AA, Kisin ER, Porter D, Schulte P, Kagan VE, Fadeel B, Castranova V: Mechanisms of pulmonary toxicity and medical applications of carbon nanotubes: Two faces of Janus? Pharmacol Ther 2009, 121(2):192-204.

2. Shvedova AA, Fabisiak JP, Kisin ER, Murray AR, Roberts JR, Tyurina YY, Antonini JM, Feng WH, Kommineni C, Reynolds J, et al: Sequential exposure to carbon nanotubes and bacteria enhances pulmonary inflammation and infectivity. Am J Respir Cell Mol Biol 2008, 38(5):579-590.

3. Shvedova AA, Kisin ER, Mercer R, Murray AR, Johnson VJ, Potapovich Al, Tyurina YY, Gorelik O, Arepalli S, Schwegler-Berry D, et al: Unusual inflammatory and fibrogenic pulmonary responses to single-walled carbon nanotubes in mice. Am J Physiol Lung Cell Mol Physiol 2005, 289(5):L698-L708.

4. Mitchell LA, Gao J, Wal RV, Gigliotti A, Burchiel SW, McDonald JD: Pulmonary and systemic immune response to inhaled multiwalled carbon nanotubes. Toxicol Sci 2007, 100(1):203-214.

5. Mitchell LA, Lauer FT, Burchiel SW, McDonald JD: Mechanisms for how inhaled multiwalled carbon nanotubes suppress systemic immune function in mice. Nat Nanotechnol 2009, 4(7):451-456.

6. Joynson DH, Wreghitt TJ: Toxoplasmosis: a comprehensive clinical guide. Cambridge, UK: Cambridge University Press; 2001.

7. Luft BJ, Hafner R, Korzun AH, Leport C, Antoniskis D, Bosler EM, Luft BJ, Hafner R, Korzun AH, Leport C, Antoniskis D, Bosler EM, Bourland DD 3rd, Uttamchandani R, Fuhrer J, Jacobson J, et al: Toxoplasmic encephalitis in patients with the acquired immunodeficiency syndrome. Members of the ACTG 077p/ANRS 009 Study Team. N Engl J Med 1993, 329(14):995-1000.

8. Montoya JG, Liesenfeld O: Toxoplasmosis. Lancet 2004, 363(9425):1965-1976.

9. Evans TG, Schwartzman JD: Pulmonary toxoplasmosis. Semin Respir Infect 1991, 6(1):51-57.

10. Huang L, Crothers K: HIV-associated opportunistic pneumonias. Respirology 2009, 14(4):474-485.

11. Murray JF, Felton CP, Garay SM, Gottlieb MS, Hopewell PC, Stover DE, Teirstein AS: Pulmonary complications of the acquired immunodeficiency syndrome. Report of a National Heart, Lung, and Blood Institute workshop. N Engl J Med 1984, 310(25):1682-1688.

12. Sacks $D$, Sher $A$ : Evasion of innate immunity by parasitic protozoa. Nat Immunol 2002, 3(11):1041-1047.

13. Yap GS, Sher A: Effector cells of both nonhemopoietic and hemopoietic origin are required for interferon (IFN)-gamma- and tumor necrosis factor (TNF)-alpha-dependent host resistance to the intracellular pathogen, Toxoplasma gondii. J Exp Med 1999, 189(7):1083-1092.

14. Courret N, Darche S, Sonigo P, Milon G, Buzoni-Gatel D, Tardieux I: CD11Cand CD11b-expressing mouse leukocytes transport single Toxoplasma gondii tachyzoites to the brain. Blood 2006, 107(1):309-316.

15. Lambert $H$, Barragan A: Modelling parasite dissemination: host cell subversion and immune evasion by Toxoplasma gondii. Cell Microbiol 2010, 12(3):292-300.

16. Lambert H, Hitziger N, Dellacasa I, Svensson M, Barragan A: Induction ofdendritic cell migration upon Toxoplasma gondii infection potentiates parasite dissemination. Cell Microbiol 2006, 8(10):1611-1623.
17. Hitziger N, Dellacasa I, Albiger B, Barragan A: Dissemination of Toxoplasma gondii to immunoprivileged organs and role of Toll/interleukin-1 receptor signalling for host resistance assessed by in vivo bioluminescence imaging. Cell Microbiol 2005, 7(6):837-848.

18. Saeij JP, Boyle JP, Grigg ME, Arrizabalaga G, Boothroyd JC: Bioluminescence imaging of Toxoplasma gondii infection in living mice reveals dramatic differences between strains. Infect Immun 2005, 73(2):695-702.

19. Candolfi $E$, Hunter CA, Remington JS: Roles of gamma interferon and other cytokines in suppression of the spleen cell proliferative response to concanavalin A and toxoplasma antigen during acute toxoplasmosis. Infect Immun 1995, 63(3):751-756.

20. Fenoy I, Giovannoni M, Batalla E, Martin V, Frank FM, Piazzon I, Goldman A: Toxoplasma gondii infection blocks the development of allergic airway inflammation in BALB/c mice. Clin Exp Immunol 2009, 155:275-284.

21. Kim JO, Jung SS, Kim SY, Kim TY, Shin DW, Lee JH, Lee JH: Inhibition of Lewis lung carcinoma growth by Toxoplasma gondii through induction of Th1 immune responses and inhibition of angiogenesis. J Korean Med Sci 2007, 22:S38-S46.

22. O'Brien KB, Schultz-Cherry S, Knoll LJ: Parasite-mediated upregulation of NK cell-derived gamma interferon protects against severe highly pathogenic H5N1 influenza virus infection. J Virol 2011, 85:8680-8688.

23. Tkach AV, Shurin GV, Shurin MR, Kisin ER, Murray AR, Young SH, Star A, Fadeel B, Kagan VE, Shvedova AA: Direct effects of carbon nanotubes on dendritic cells induce immune suppression upon pulmonary exposure. ACS Nano 2011, 5(7):5755-5762.

24. Barragan A, Hitziger N: Transepithelial migration by Toxoplasma. Subcell Biochem 2008, 47:198-207.

25. Channon JY, Seguin RM, Kasper LH: Differential infectivity and division of Toxoplasma gondii in human peripheral blood leukocytes. Infect Immun 2000, 68(8):4822-4826.

26. Aliberti J: Host persistence: exploitation of anti-inflammatory pathways by Toxoplasma gondii. Nat Rev Immunol 2005, 5(2):162-170.

27. Liu CH, Fan YT, Dias A, Esper L, Corn RA, Bafica A, Machado FS, Aliberti J: Cutting edge: dendritic cells are essential for in vivo IL-12 production and development of resistance against Toxoplasma gondii infection in mice. J Immunol 2006, 177(1):31-35.

28. McKee AS, Dzierszinski F, Boes M, Roos DS, Pearce EJ: Functional inactivation of immature dendritic cells by the intracellular parasite Toxoplasma gondii. J Immunol 2004, 173(4):2632-2640.

29. Pepper M, Dzierszinski F, Wilson E, Tait E, Fang Q, Yarovinsky F, Laufer TM, Roos D, Hunter CA: Plasmacytoid dendritic cells are activated by Toxoplasma gondii to present antigen and produce cytokines. I Immunol 2008, 180(9):6229-6236.

30. Reis e Sousa C, Hieny S, Scharton-Kersten T, Jankovic D, Charest H, Germain RN, Sher A: In vivo microbial stimulation induces rapid CD40 ligandindependent production of interleukin 12 by dendritic cells and their redistribution to T cell areas. J Exp Med 1997, 186(11):1819-1829.

31. Blader IJ, Saeij JP: Communication between Toxoplasma gondii and its host: impact on parasite growth, development, immune evasion, and virulence. APMIS 2009, 117(5-6):458-476.

32. Munoz M, Liesenfeld O, Heimesaat MM: Immunology of Toxoplasma gondii. Immunol Rev 2011, 240(1):269-285.

33. Wei S, Marches F, Borvak J, Zou W, Channon J, White M, Radke J, CesbronDelauw MF, Curiel TJ: Toxoplasma gondii-infected human myeloid dendritic cells induce T-lymphocyte dysfunction and contact-dependent apoptosis. Infect Immun 2002, 70(4):1750-1760.

34. Mordue DG, Monroy F, La Regina M, Dinarello CA, Sibley LD: Acute toxoplasmosis leads to lethal overproduction of Th1 cytokines. $J$ Immunol 2001, 167(8):4574-4584.

35. Sharma SD, Mullenax J, Araujo FG, Erlich HA, Remington JS: Western Blot analysis of the antigens of Toxoplasma gondii recognized by human IgM and IgG antibodies. J Immunol 1983, 131(2):977-983.

doi:10.1186/1743-8977-9-16

Cite this article as: Swedin et al:: Pulmonary exposure to single-walled carbon nanotubes does not affect the early immune response against Toxoplasma gondii. Particle and Fibre Toxicology 2012 9:16. 